\title{
The Role of Supervision in Preventing Burnout among Professionals Working with People in Difficulty
}

\author{
Iasmina Iosim ${ }^{1}$, Patricia Runcan ${ }^{2}$, Virgil Dan ${ }^{2}$, Bogdan Nadolu ${ }^{3, *}$, Remus Runcan ${ }^{4}\left(\mathbb{D}\right.$ and Magdalena Petrescu ${ }^{5}$ \\ 1 Economics and Finance Company Department, Faculty of Management and Rural Tourism, \\ Banat's University of Agricultural Science and Veterinary Medicine "King Mihai I of Romania", \\ 300645 Timisoara, Romania; iasminaiosim@usab-tm.ro \\ 2 Department of Social Work, The Faculty of Sociology and Psychology, West University of Timisoara, \\ 300223 Timisoara, Romania; patricia.runcan@e-uvt.ro (P.R.); virgil.dan68@e-uvt.ro (V.D.) \\ 3 Department of Sociology, The Faculty of Sociology and Psychology, West University of Timisoara, \\ 300223 Timisoara, Romania \\ 4 Department of Pedagogy, Psychology and Social Work, Faculty of Educational Science, \\ Psychology and Social Work, Aurel Vlaicu University of Arad, 310032 Arad, Romania; remus.runcan@uav.ro \\ 5 Department for Teaching Training, West University of Timisoara, 300223 Timisoara, Romania; \\ magdalena.petrescu@e-uvt.ro \\ * Correspondence: bogdan.nadolu@e-uvt.ro; Tel.: +40-723-235371
}

Citation: Iosim, I.; Runcan, P.; Dan, V.; Nadolu, B.; Runcan, R.; Petrescu, M. The Role of Supervision in Preventing Burnout among Professionals Working with People in Difficulty. Int. J. Environ. Res. Public Health 2022, 19, 160. https://doi.org/ 10.3390/ijerph19010160

Academic Editor: Paul B. Tchounwou

Received: 25 November 2021

Accepted: 22 December 2021

Published: 24 December 2021

Publisher's Note: MDPI stays neutral with regard to jurisdictional claims in published maps and institutional affiliations.

Copyright: (C) 2021 by the authors. Licensee MDPI, Basel, Switzerland. This article is an open access article distributed under the terms and conditions of the Creative Commons Attribution (CC BY) license (https:// creativecommons.org/licenses/by/ $4.0 /)$.

\begin{abstract}
The value of people in their various dimensions is a priority in the postmodern era. In this respect, programs are being implemented for disadvantaged social categories to compensate for differences, reduce discrepancies, and integrate marginalized people into society. This, however, is not easy, and the work of professionals with people in difficulty is frequently difficult, consuming multiple resources and, sometimes, leading to burnout. The professions involved in the recovery work of people in difficulty provide social, medical, psychological, and spiritual assistance services in order to restore or increase the well-being of disadvantaged people or social groups. This study presents an analysis of burnout among social workers and clerics and the effect of supervision on burnout. In support of this, a sociological survey $(n=502)$ was conducted on a convenience sample of Romanian social workers and clerics in June 2018. The main conclusion of the study is that supervising professionals working with people in difficulty significantly reduces the risk of burnout.
\end{abstract}

Keywords: supervision; social workers; clerics; people in difficulty; burnout

\section{Introduction}

Supervision can be defined as the act or function of supervising (overseeing a process, work, workers, etc., during the execution of work or performance).

Speaking of the plethora of definitions of supervision in social work, Reference [1] noted: "what is common in these definitions is that they describe social work supervision as a process, activity, and relationship(s), based in an organizational professional and personal mandate, with designated roles, and boundaries, in which particular functions are performed with the aim of facilitating the best/competent service/practice with clients".

Over time, supervision has seen its meaning change: first, it was a supportive and reflective space for social workers, then it was assimilated with counselling-/psychotherapybound models of supervision, before finally moving its focus "from the person doing the work to the work itself" [2].

Its primary functions are "administrative case management, reflecting on and learning from practice, personal support, mediation (in which the supervisor acts as a bridge between the individual staff member and the organization), and professional development" [3].

O'Donoghue emphasized the uniqueness of supervision in social work through the fact that, operating within the paradigm of social work, "social work and social workers 
view the world and construct the social work language, principles, beliefs, assumptions and methods" [4]. This perspective adds to the dedication to the principles of anti-oppressive and anti-discriminatory practice, of human rights and social justice, and of power and empowerment, giving the social assistance profession a leading place between other professions and disciplines $[5,6]$.

In particular situations, such as the COVID-19 pandemic, the role of supervisors is of particular importance, given that the impacts of the pandemic have been minimized by such interventions as "feedback of information provided by middle managers and supervisors", organizational culture facilitating interdisciplinary teamwork, and participative leadership styles [7].

In their review of the research on supervision in social work, Reference [1] came to the conclusion that research in this field should "focus on evaluating the effectiveness of supervision practices across all of the various formats in order to develop empirically supported supervision practice models; discover how supervision practice contributes to client outcomes and involve clients in supervision research; develop an international understanding of the nature and practice of supervision; be more widely known within the social work profession".

In Romania, after 1989, supervision was either not known about in most state institutions or was perceived as control and supervision, mainly because of the mentality of the employees.

Pastoral supervision differs from supervision in social work only from the perspective of the religious/spiritual approach. It is, according to The Association for Pastoral Supervision and Education [8], a boundaried, intentional, planned, and regular space where the supervisor meets the supervisee(s), and a way of growing in accountability, mutual learning, quality of presence, response to challenges, role competence, self-awareness, spiritual/theological reflection, and vocational identity, as well as being attentive to issues of fitness to practice, impact of the work upon all concerned parties, management of boundaries, professional identity, and skill development, based on practice that is, psychologically, and spiritually/theologically informed, and is contextually sensitive.

In Romania, pastoral supervision was either of secondary importance or completely absent among the over 22,000 professionals (chaplains, confessors, faith community nurses or parish nurses, imams, parish workers, pastoral careers, pastoral counsellors, pastors, priests, or rabbis) working in 2015 [9].

Occupational stress [10], compassion fatigue [11], secondary traumatic stress [12], and vicarious trauma [13] can all lead to a syndrome called burnout [14], job burnout [15] or professional burnout [16]—defined as "physical or mental collapse caused by overwork or stress" (Lexico). "Burnout was found to mediate the association of family-to-work conflict] with workplace injuries" [17].

Burnout varies depending on context. During the COVID-19 pandemic, for instance, burnout components in health workers have been predicted by a wide variety of factors, such as: emotional exhaustion, by anxiety, the burden of treating suspected COVID-19 patients, depression, fear of infection, marital status, sex; depersonalization, by anxiety, endless months of work in the current department, depression, job category, dissatisfaction with work environment; and personal accomplishment, by job stress, socioeconomic status, workload of directly interacting with patients [18-21].

Burnout can also occur in educational environments, particularly during such events as the first wave of the COVID-19 pandemic, for instance [22], when "an increase in the level of educational burnout, a decrease in life satisfaction, and the use of negative strategies of coping with stress were accompanied by a deteriorated mental condition of students, with female respondents scoring higher on the scale of disorders in comparison to males".

Job demands and resources affect burnout in a different way: job demands are "positively associated with burnout", while job resources are "negatively associated with burnout", and relations are "partially mediated by state mindfulness" ("a state of consciousness during which an individual actively engages in purposeful awareness and 
attention to the present moment" [23]) — job demand has a slight negative direct effect on mindfulness, while job resources have a strong, positive direct effect on mindfulness.

Burnout chases away over $50 \%$ of U.S.A. clerics in their first five years of work [24], kindergarten teachers leading them to new careers in Spain [25], and almost 50\% of Romania's trained clerics who choose to reconvert professionally or not to work at all.

Burnout caused by prolonged professional stress can be prevented by helping professionals recognize, comprehend and manage work-related stress with professional supervision as additional support [26].

In a comprehensive approach, Sălășan and Rață define the people and groups in difficulty as: refugees seeking protection; asylum applicants expecting to be granted habitation rights willing to actively integrate into the society and customs, including employment; infant carefulness and watchfulness for incapacitated children aged 0-4 and extra-school watch and care kids until 12 years of age; people aged over 55 presenting specific symptoms or being affected by dementia; seniors over 55 years of age requiring assistance in their daily lives; former and currently addicted persons isolated form the active part of the society; former and currently convicted persons having difficulties reintegrating into the society after serving time for unlawful conduct; immigrants; people in long-term unemployment with no defined perspective of re-employment; persons affected by autism, children or adults presenting specific autistic syndrome symptoms combined or not with other forms of incapacities; persons affected by burnout or presenting the distress of burnout symptoms originating from a professional or private environment and where full employment is provisionally not possible; persons presenting incapacities of psychical or physical nature, with challenges or impairments preventing them from complete nondiscriminatory interaction with the society; persons previously affected by accidents or diseases resulting in severe brain damage and facing constraints when attempting to act normally in society; youngsters originating from or integrated in education systems dealing with special needs related to psychological challenges and/or interaction issues; youngsters somewhat mentally challenged and requiring assistance and support to actively integrate into society [27].

The professions involved in the recovery of people in difficulty are collected under the generic title of "caring profession" ("a job that involves looking after other people, such as nursing, teaching, or social work"-Lexico) or "helping professions" ("professions that nurture the growth of or address the problems of a person's physical, psychological, intellectual, emotional or spiritual well-being") such as education, life coaching, medicine, ministry (through pastoral intervention, spiritually-oriented intervention [28]), nursing, psychological counselling, psychotherapy, and social work (through counselling).

According to Stevenson, in the context of professional supervision, the purpose of this action may lead to: (i) raising awareness of the roles and responsibilities of social workers; (ii) encouraging social workers to pursue professional goals; (iii) increasing the capacity to understand people, problems, and situations; (iv) promoting personal and professional development; and (v) ensuring a positive environment in which the practice of each social worker can be analyzed and reviewed [29].

Wallbank and Hatton (2011) conclude that supervision in its various forms has been shown to be effective in increasing personal job satisfaction, reducing stress and burnout, and improving the quality of professional services [30-32]. Regarding cross-supervision, although work performance is higher when the supervisor is from the same profession, the supervised people perceived trust and a safe environment as more important [33].

Kavanagh, Spence, Strong, Wilson, Sturk, and Crow, identify the key elements of a valuable supervisor as clinical expertise and the ability to provide new and relevant handson knowledge and promote learning in a safe and respectful environment [34]. Supervision is by far the most important factor influencing the ethical decision-making process in social work [35]. 


\section{Materials and Methods}

This paper presents a comparative analysis of the level of burnout in two types of professionals working with people in difficulty in Romania-social workers and clerics. The role of supervision in preventing burnout has also been studied by identifying maximum impact elements in the prevention of burnout. The analysis of burnout was carried out on three distinct underlying dimensions: (i) decreasing personal satisfaction as a result of reducing personal achievements; (ii) emotional burnout; and (iii) depersonalization.

This approach started from a research question regarding the impact of supervision on preventing and controlling burnout in the 7000 social workers and 15,000 clerics working with people in difficulty in Romania.

\section{Objectives and Hypotheses}

The research objectives are:

1. To measure the level of burnout among social workers and clerics in Romania and its correlation with professional supervision.

2. To identify the effects of burnout on professionals working with people in difficulty at the level of personal satisfaction, emotional burnout, and depersonalization.

To achieve these specific objectives, the following research hypotheses have been formulated:

1. Professional working with people in difficulty and not benefitting from quality professional supervision is at higher risk of developing the burnout syndrome. In this study, the level of burnout is determined using the Maslach Burnout Inventory (MBI) [36] in relation to the level of supervision satisfaction determined using the Supervision Quality Assessment Scale (SQAS) [37].

2. Professional working with people in difficulty and with a high score of depressive symptoms is at higher risk of developing the burnout syndrome. High depression score professionals were identified with the Hospital Anxiety and Depression Scale (HADS) [38,39]. The level of burnout was then determined using the MBI.

3. Clerics are at higher risk of developing emotional burnout than social workers. The level of emotional burnout was determined by the corresponding subscale identifying its specific items in the MBI depending on the professional (social worker or cleric).

Burnout is measured using the MBI. This questionnaire was chosen to contrast the Copenhagen Burnout Inventory (CBI) due to its robustness, reliability, and much wider use. At citations level, the ratio is 10:1 in favor of MBI. A score between 25 and 50 shows a low level of burnout; between 51 and 75 shows an average level of burnout; above 75 points shows a high level of burnout.

Although, for a holistic assessment of burnout, a score is taken for the whole questionnaire, there are three dimensions that lead to burnout: emotional burnout consisting of nine items, depersonalization consisting of six items, and the reduction of personal satisfaction as a result of a reduction of professional efficiency and achievements. To eliminate the effects of monotony, eight inverse quotation items were intercalated, i.e., very rarely -5 points, rarely -4 points, sometimes -3 points, frequently -2 points, and very frequently-1 point. Burnout was analyzed both as a whole and per dimensions for a double purpose: on the one hand, to analyze whether the dimensions of burnout correlate negatively with the dimensions of supervision, which is explained in relation to the scale of supervision; and, on the other, to see if, in the case of clerics, a high level of emotional burnout can operate in parallel with elevated levels of personal satisfaction as stated by Barnard and Curry [40].

The second part of the applied questionnaire included the HADS, from which seven items were identified to measure depressive symptoms. This was chosen because it is by far the most used depression measurement scale. Unlike the other depressive-symptom measurement scales containing more than 15 items, it was possible to opt for the HADS as the subscale measures depressive symptoms with seven items, which is useful only as a predictor of burnout, but is not the main purpose of this research. 
The third part of the applied instrument included a SQAS containing a scale built from the three functions of a supervisor: administrative, educational, and supportive. Like the $\mathrm{MBI}$, this questionnaire also uses a five-point Likert scale, namely: 1-very rarely, 2-rarely, 3-sometimes, 4-frequently, 5-very frequently. A score between 25 and 50 reflects low quality supervision; between 51 and 75 reflects medium quality supervision; and above 76 points to high quality supervision.

The Q4 scale measures spirituality with a scale (RSS) adapted after Runcan [41], aiming at several measurable aspects of spirituality as effects in relation to God. This scale was chosen to measure more than religiosity and to develop a sufficiently comprehensive scale for both religious cults represented in Romania and professionals who are not religious people.

The research population consisted of 7000 social workers and 15,000 clerics from Romania Romanian-speaking people who have at least one email address. The research sample was non-probabilistic and consisted of a 502-person availability batch, 247 social workers and 255 clerics, with a five-point margin of error. Data collection was accomplished from 13 June to 28 June, 2018, using Google Docs through professional networks. Respondents were professionals from all the counties of Romania. Of course, distribution is not even because of the reluctance or even refusal to supply personal and professional data. The study was conducted according to the guidelines of the Declaration of Helsinki, and approved for publication by the Institutional Review Board of AUREL VLAICU University of Arad, Romania (protocol code 03/3 August 2021). A copy of the questionnaire was provided in Appendix A. The database is freely accessible at http://doi.org/10.3886/E155301V1 (accessed on 23 November 2021).

\section{Results}

The scales applied have a very good internal consistency reliability, measured by Cronbach's alpha: 0.91 for MBI, 0.75 for HADS, 0.99 for SQAS and 0.89 for RSS. The socio-demographic structure of the sample investigated is shown in Table 1.

Table 1. Socio-demographic structure of the sample.

\begin{tabular}{|c|c|c|c|}
\hline \multirow{2}{*}{\multicolumn{2}{|c|}{ Factual Data }} & \multicolumn{2}{|c|}{ Respondents } \\
\hline & & $\mathbf{N}$ & $\%$ \\
\hline \multirow{2}{*}{ Profession } & social workers & 247 & 49.2 \\
\hline & clerics & 255 & 50.8 \\
\hline \multirow{2}{*}{ Gender } & male & 229 & 45.6 \\
\hline & female & 273 & 54.4 \\
\hline \multirow{5}{*}{ Age } & 21-30 years & 66 & 13.1 \\
\hline & $31-40$ years & 168 & 33.5 \\
\hline & $41-50$ years & 182 & 36.3 \\
\hline & 51-60 years & 76 & 15.1 \\
\hline & $60+$ years & 10 & 2.0 \\
\hline \multirow{4}{*}{ Education } & high school & 34 & 6.8 \\
\hline & college & 208 & 41.4 \\
\hline & master's degree & 234 & 46.6 \\
\hline & doctor's degree & 26 & 5.2 \\
\hline \multirow{4}{*}{ Seniority } & $0-5$ years & 105 & 20.9 \\
\hline & 6-15 years & 166 & 33.1 \\
\hline & $16-30$ years & 204 & 40.6 \\
\hline & $30+$ years & 27 & 5.4 \\
\hline \multirow{2}{*}{ Work environment } & rural & 91 & 18.1 \\
\hline & urban & 411 & 81.9 \\
\hline \multirow{2}{*}{ Marital status } & married & 430 & 85.7 \\
\hline & single & 72 & 14.3 \\
\hline
\end{tabular}


The results of the four scales (MBI, HADS, SQAS, and RSS) applied in a comparative cross-tabular between social workers and clerics are shown in Figures 1-4 below:

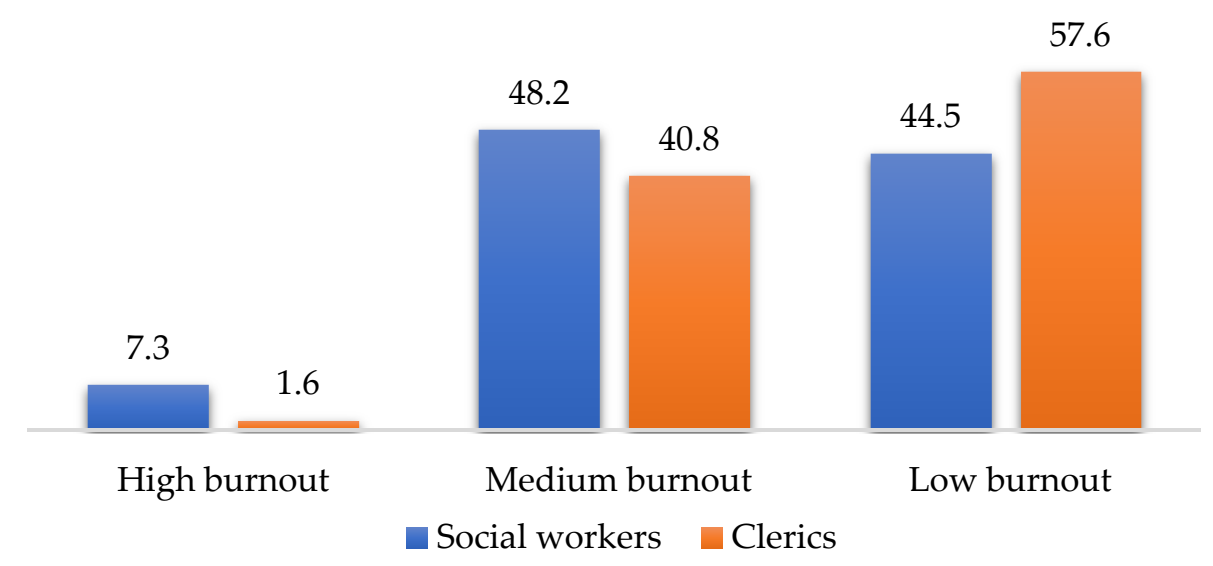

Figure 1. MBI scores for social workers and clerics.

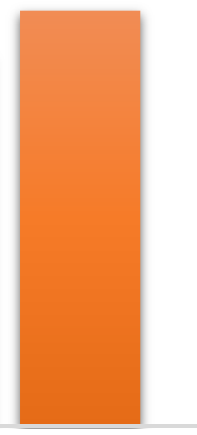

High level of depression Medium level of depression Low level of depression

$$
\text { - Social workers Clerics }
$$

Figure 2. HADS scores for social workers and clerics.

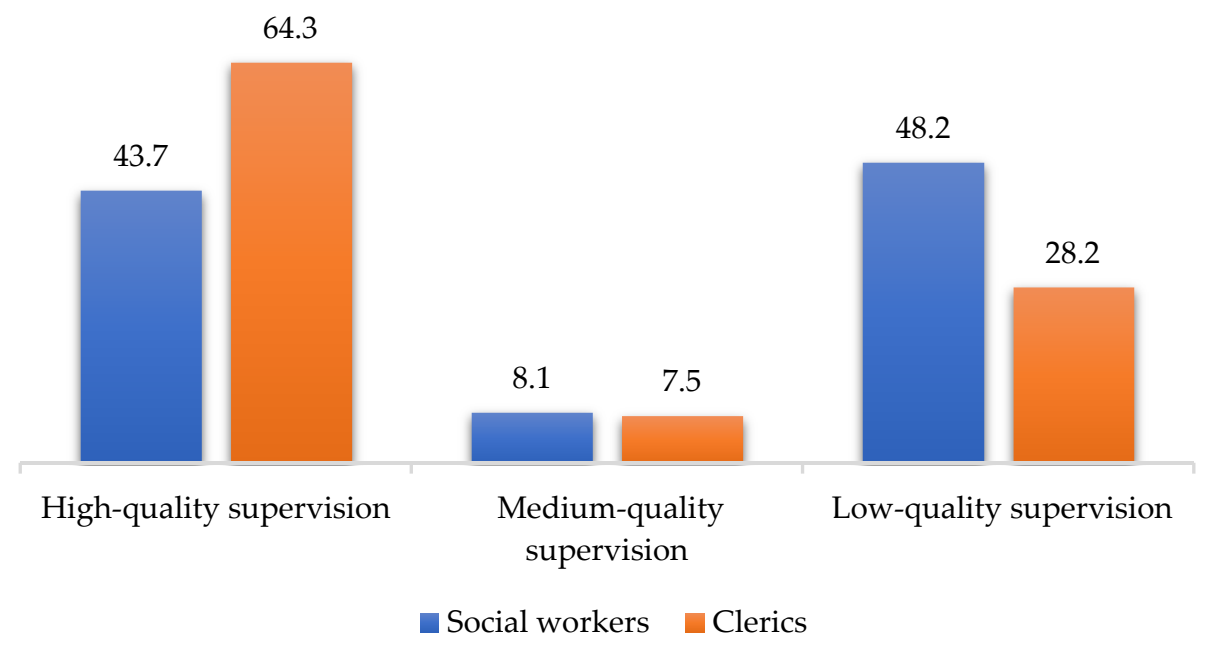

Figure 3. SQAS scores for social workers and clerics. 


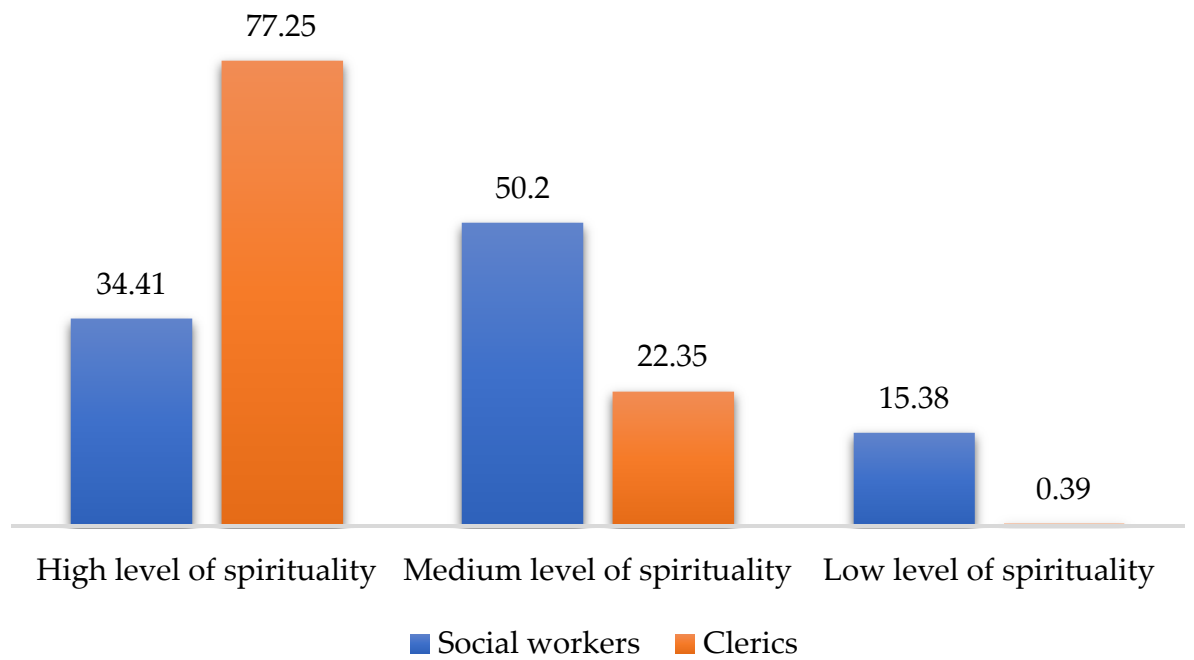

Figure 4. RSS scores for social workers and clerics.

According to these results, there are statistically significant differences between clerics and social workers (chi square $=15.121, \mathrm{df}=2, p<0.001$ ), in the sense that social workers recorded higher burnout scores than clerics (MBI). Additionally, the level of depressive symptoms (HADS) is $9 \%$ higher among social workers than clerics (the differences being not statistically significant). Regarding supervision (SQAS), there were statistically significant differences (chi square $=22.999, \mathrm{df}=2, p<0.001$ ) in the sense that clerics recorded significantly higher scores (above 20\%) compared to social workers in quality of supervision. A completely different situation between the two sub-samples was obtained in the level of spirituality, the clerics having, as expected, a $40 \%$ higher level of spirituality than social workers (chi square $=39.374, \mathrm{df}=2, p<0.001$ ). The comparative analysis through the median and percentiles 25-75 between the scores obtained by the two subgroups (social workers and clerics) in the four scales reflects a clear differentiation (Table 2).

Table 2. Comparative analysis of the median and percentiles $25-75$ between the scores obtained in the four scales by the two subgroups (social workers and clerics).

\begin{tabular}{|c|c|c|c|c|c|c|c|c|c|}
\hline \multicolumn{3}{|c|}{ Clergy/Social Worker } & \multicolumn{7}{|c|}{ Percentiles } \\
\hline & & & 5 & 10 & 25 & 50 & 75 & 90 & 95 \\
\hline \multirow{8}{*}{$\begin{array}{l}\text { Weighted } \\
\text { Average } \\
\text { (Definition) }\end{array}$} & \multirow{2}{*}{ MBI score } & $\mathrm{C}$ & 30.80 & 33.00 & 40.00 & 48.00 & 57.00 & 64.00 & 70.00 \\
\hline & & SW & 33.00 & 35.80 & 42.00 & 54.00 & 63.00 & 71.20 & 78.60 \\
\hline & \multirow{2}{*}{ HADS score } & $\mathrm{C}$ & 0.0000 & 0.1429 & 0.2857 & 0.4286 & 0.7143 & 1.0000 & 1.2857 \\
\hline & & SW & 0.0000 & 0.1429 & 0.2857 & 0.5714 & 0.8571 & 1.2857 & 1.5143 \\
\hline & \multirow{2}{*}{ SQAS score } & $\mathrm{C}$ & 0.00 & 0.00 & 0.00 & 94.00 & 107.00 & 120.00 & 125.00 \\
\hline & & SW & 0.00 & 0.00 & 0.00 & 61.00 & 99.00 & 115.20 & 123.00 \\
\hline & \multirow{2}{*}{ RSS score } & $\mathrm{C}$ & 16.60 & 18.00 & 21.00 & 24.00 & 26.00 & 28.00 & 29.00 \\
\hline & & SW & 5.40 & 8.00 & 12.00 & 17.00 & 22.00 & 26.00 & 28.00 \\
\hline \multicolumn{2}{|c|}{ Test Statistics ${ }^{\mathrm{a}}$} & \multicolumn{2}{|c|}{ MBI Score } & \multicolumn{2}{|c|}{ HADS Score } & \multicolumn{2}{|c|}{ SQAS Score } & \multicolumn{2}{|c|}{ RSS Score } \\
\hline \multicolumn{2}{|c|}{ Mann-Whitney U } & \multicolumn{2}{|c|}{$24,948.500$} & \multicolumn{2}{|c|}{$28,263.000$} & \multicolumn{2}{|c|}{$23,822.500$} & \multicolumn{2}{|c|}{$13,809.000$} \\
\hline \multirow{2}{*}{\multicolumn{2}{|c|}{$\begin{array}{c}\text { Wilcoxon W } \\
\text { Z }\end{array}$}} & \multicolumn{2}{|c|}{$57,588.500$} & \multicolumn{2}{|c|}{$60,903.000$} & \multicolumn{2}{|c|}{$54,450.500$} & \multicolumn{2}{|c|}{$44,437.000$} \\
\hline & & \multicolumn{2}{|c|}{-4.029} & \multicolumn{2}{|c|}{-2.001} & \multicolumn{2}{|c|}{-4.826} & \multicolumn{2}{|c|}{-10.900} \\
\hline \multicolumn{2}{|c|}{ Asymp Sig. (2-tailed) } & \multicolumn{2}{|c|}{0.000} & \multicolumn{2}{|c|}{0.045} & \multicolumn{2}{|c|}{0.000} & \multicolumn{2}{|c|}{0.000} \\
\hline
\end{tabular}

${ }^{\text {a }}$ Grouping Variable: C/AS.

Thus, three of the four scales provide high statistically significant results $(p<0.001)$, i.e., the MBI, the SQAS and the RSS. The fourth scale, the HADS, restricted to depression items, also provides statistically significant results $(p<0.05)$. The results also reflect a higher level of burnout and a higher score of depressive symptoms in social workers than in clerics, while supervision quality and spirituality score higher in clerics than in social workers. 
The correlation analysis between these scales reflects a high level of interdependence between them:

- There is an inversely proportional monotonous relationship between supervision quality and burnout $(\mathrm{N}=502$, rho $=-0.348, p<0.001)$, which confirms hypothesis no. 1, namely, when supervision is missing or low quality, the risk of burnout increases.

- There is an inversely proportional monotonous relationship between level of spirituality and level of burnout (rho $=-0.343, p<0.001$ ), which mean that when spirituality is missing or of low quality, the risk of emotional burnout increases.

- There is an inversely proportional monotonous relationship between the administrative function of supervision and the level of emotional burnout (rho $=-0.341$, $p<0.001$, which means that when the administrative function of supervision is missing or of low quality, the risk of emotional burnout increases.

- There is an inversely proportional monotonous relationship between the educational function of supervision and the level of depersonalization (rho $=-0.210, p<0.001$ ), which means that when the educational function of supervision is missing or of low quality, the risk of depersonalization increases.

- There is an inversely proportional monotonous relationship between the supportive function of supervision and the reduction of personal satisfaction (rho $=-0.299$, $p<0.001$ ), which means that when the supportive function of supervision is missing or of low quality, the risk of reducing personal satisfaction increases.

Burnout can be engendered by several factors with different impacts on subjects depending on the labor context and individual features. To quantify the amplitude of the impact of supervision, depressive symptoms, spirituality and socio-demographic variables on burnout, a regression model is used. Thus, the low level of burnout in professionals (social workers and clerics) working with people in difficulty is determined by a highquality supervision (chi square $=25.361, \mathrm{df}=2, p<0.001$ ), a high level of spirituality (chi square $=5.399, \mathrm{df}=1, p<0.020$ ), and the absence of depressive trends (chi square $=105.596$, $\mathrm{df}=2, p<0.001$ ). Burnout is not influenced by age or education, but has a significant statistical differentiation for the gender variable (chi square $=10.689, \mathrm{df}=1, p<0.020$ ), women being more prone to burnout than men. By applying a binomial logistic regression model, the distribution shown in Table 3 below is obtained.

Table 3. Factors influencing burnout in social workers and clerics.

\begin{tabular}{cccccc}
\hline & B & $p$ & OR & \multicolumn{2}{c}{$\mathbf{9 5 \% \text { CI for OR }}$} \\
\cline { 5 - 6 } & & & & Min & Max \\
\hline $\begin{array}{c}\text { Levels of supervison quality } \\
\text { medium-quality supervision } \\
\text { high-quality supervision }\end{array}$ & -0.161 & 0.700 & 0.851 & 0.375 & 1.933 \\
\hline Medium and high depression & 0.674 & 0.003 & 1.962 & 1.264 & 3.045 \\
\hline Gender (1) & 2.160 & 0.000 & 8.675 & 5.334 & 14.108 \\
\hline Age (three intervals) & 0.395 & 0.271 & 1.484 & 0.735 & 2.997 \\
Age interval (1) & 0.024 & 0.917 & 1.024 & 0.656 & 1.598 \\
Age interval (2) & 0.045 & 0.881 & 1.046 & 0.579 & 1.891 \\
\hline Education & & 0.268 & & & \\
Education (1) & 0.183 & 0.675 & 1.200 & 0.511 & 2.817 \\
Education (2) & 0.486 & 0.263 & 1.626 & 0.695 & 3.805 \\
\hline Level of spirituality (1) & 0.449 & 0.272 & 1.566 & 0.703 & 3.487 \\
\hline Social workers and clerics & 0.073 & 0.839 & 1.076 & 0.531 & 2.180 \\
\hline Constant & -0.920 & 0.000 & 0.398 & & \\
\hline
\end{tabular}

In the case of professionals benefiting from high-quality supervision, the probability of not developing burnout is twice as high $(\mathrm{OR}=1.962, p<0.05)$, while in those with 
a medium and high level of depression, the probability of developing burnout is nine times higher $(\mathrm{OR}=8.675, p<0.001)$. It is also true that quality supervision provided by the supervisor to the professional working with people in difficulty, and assumed by the latter, will protect him/her with a 3 to 1 share of the danger of burnout. The second predictor is of a psychological nature, namely depressive symptoms. A medium or high score indicates the risk of burnout syndrome with a 5-17 to 1 share. Among personal factors, the spiritual factor has a positive influence in preventing personal burnout syndrome, along with individual factors, such as increased levels of education, age, or seniority. Women also run a higher risk of burnout syndrome than men.

\section{Discussion}

In this research, the goal was to analyze the role of supervision in two categories of professionals in Romania working with people in difficulty, namely social workers and clerics to prevent burnout. Analyzing burnout in two categories of professionals, there is a statistically significant difference between clerics and social workers, in the sense that social workers had higher burnout scores than clerics.

Measuring the level of depressive symptoms, it was clear that only three of the seven items had statistically significant outcomes, while three other items only approached the significance threshold. Expressed as a percentage, the level of depressive symptoms among social workers is $9 \%$ higher than in clerics. As regards supervision, the results were statistically significant, in the sense that clerics recorded $20 \%$ higher scores in the quality of supervision than social workers. The results were also statistically significant in terms of spirituality: as expected, clerics had $40 \%$ higher scores than social workers.

Comparisons between groups (made with the Mann-Whitney U test) show a higher level of burnout and a higher score of depressive symptoms in social workers than in clerics. Three of the four scales produced strong statistically significant outcomes $(p<0.001)$, i.e., Scale 1 (MBI), Scale Q3 (SQAS) and Scale 4 (RSS), while Scale 2 (HADS), restricted to depression items, also provides statistically significant results $(p<0.05)$.

Correlation analyses have also shown that there is an inversely proportional medium power relationship ( $r h o=-0.348$ ) between the level of burnout and supervision quality $(p<0.001)$. When supervision is missing or low quality, the risk of burnout increases; and vice versa, when supervision is high quality, the risk of burnout decreases. There is also an inversely proportional medium power relationship (rho $=-0.343$ ) between the level of burnout and the level of spirituality $(p<0.001)$. When spirituality is missing or low quality, the risk of burnout increases; and vice versa, when spirituality is high quality, the risk of burnout decreases.

As for the functions of supervision, there is an inversely proportional medium power relationship (rho $=-0.341$ ) between the level of emotional burnout and the administrative function of supervision $(p<0.001)$; that is, when the administrative function of supervision is missing or low quality, the risk of emotional burnout increases. There is also an inversely proportional low-quality power relationship $(\mathrm{rho}=-0.210)$ between the level of depersonalization and the educational function of supervision $(p<0.001)$; that is, when the educational function of supervision is missing or low quality, the risk of depersonalization increases. On the other hand, there is an inversely proportional monotonous power relationship (rho $=-0.299$ ) between the level of reduction of personal satisfaction and the supportive function of supervision $(p<0.001)$, i.e., when the supportive function of supervision is missing or low quality, personal satisfaction decreases.

There is also a higher level of emotional burnout among social workers than clerics, the differences between the clerics' score (2.00) and the social workers' score (2.22) being statistically significant $(p<0.001)$. Following the regression analysis, it can also be concluded that professionals working with people in difficulty who have a high score of depressive symptoms run a 5-17 times greater risk of developing a burnout syndrome than professionals who do not show depressive symptoms. Complementarily, quality supervision provided and assumed by professionals working with people in difficulty will 
provide three times the amount of protection from the risk of burnout. Among personal factors, the spirituality factor has a positive influence in preventing the burnout syndrome, along with education, age, or seniority. Women also run a higher risk of burnout syndrome than men.

One of the main limitations of this research is that the conclusion represent mostly general trends and the data cannot be generalized, as the sample was a non-probabilistic one. Also, the office workers, not being immediately considered as caregivers, might have lower values in some burnout sub-scales as taken from the MBI.

As other limits of the study, it should be noted that there are variables that can influence burnout in professionals working with people in difficulty, which were not included in this study but that could be the subject of future research. Regarding supervision, interviewing or mentoring, although the satisfaction of the professional supervised was measured and compared, there may be some differences between the supervision or interviewing of the social workers and the mentoring of clerics. Even in certain clerical traditions, mentoring may have certain features influencing its effectiveness just like, in the supervision of different categories of social workers, there are various schools with different focuses. The history of supervision in supportive professions shows that each profession develops its own tradition and literature in the field [42-44].

\section{Conclusions}

Finally, it can be said that burnout in social workers and clerics in Romania working with people in difficulty can be prevented primarily through professional supervision, a profession that is, unfortunately, at an incipient stage of development in Romania. At present, in the two professions, the function of supervision is taken over by interviewing (by colleagues) and mentoring (especially in clerics, by a colleague, a hierarchical superior, or even a confessor). The conclusions of this research confirm the results of other studies on professionals who work with people in difficulty in other countries and cultures, as well as the need for quality supervisions in three areas: administrative, educational, and supportive to prevent burnout.

A longitudinal study of supervision and spirituality influence would also provide valuable information on the prevention of burnout in the professionals working with people in difficulty, namely social workers and clerics. One of the necessary research directions in the future is, according to Carpenter [3] the feedback from beneficiaries of social services regarding the effects of the professional supervision of social services. The conclusions in this area come from correlations made mainly in the U.S.A. on the positive results from these services (idem).

Author Contributions: Conceptualization, V.D. and P.R.; methodology, V.D.; software, V.D.; validation, V.D., P.R. and B.N.; formal analysis, V.D.; investigation, V.D.; resources, I.I. and R.R.; data curation, V.D. and B.N.; writing-original draft preparation, V.D. and B.N.; writing-review and editing, B.N. and M.P.; visualization, R.R. and M.P.; supervision, P.R.; project administration, R.R.; funding acquisition, I.I. All authors have read and agreed to the published version of the manuscript.

Funding: This paper is funded by Banat's University of Agricultural Sciences and Veterinary Medicine "King Mihai I of Romania" and the Research Institute for Biosecurity and Bioengineering Timisoara, Romania.

Institutional Review Board Statement: The study was conducted according to the guidelines of the Declaration of Helsinki, and approved by the Institutional Review Board of AUREL VLAICU University of Arad, Romania (protocol code 03/3 August 2021).

Informed Consent Statement: Informed consent was obtained from all subjects involved in the study.

Data Availability Statement: The database is freely accessible at http:/ / doi.org/10.3886/E155301V1 (accessed on 23 November 2021).

Acknowledgments: The authors gratefully acknowledge the contributions of Georgeta Rata and Graham Clarke in helping to translate the manuscript into English. 
Conflicts of Interest: The authors declare no conflict of interest. The funders had no role in the design of the study; in the collection, analyses, or interpretation of data; in the writing of the manuscript, or in the decision to publish the results.

\section{Appendix A}

The applied questionnaire

Questionnaire

This questionnaire is part of the research tools of a study regarding professional burnout among Romanian social workers and clergy. Please answer the questions below according to your opinion. There are no right or wrong answers. What matters is your own opinion on the aspects referred to in the questionnaire. The questionnaire is anonymous, and the data thus obtained will be processed statistically.

Q 1. the following questions refer to your work place. Please, read them carefully and tick one of the response variants that best matches your current state.

Table A1. 1-very rarely/2-rarely/3-sometimes/4-frequently/5-very frequently.

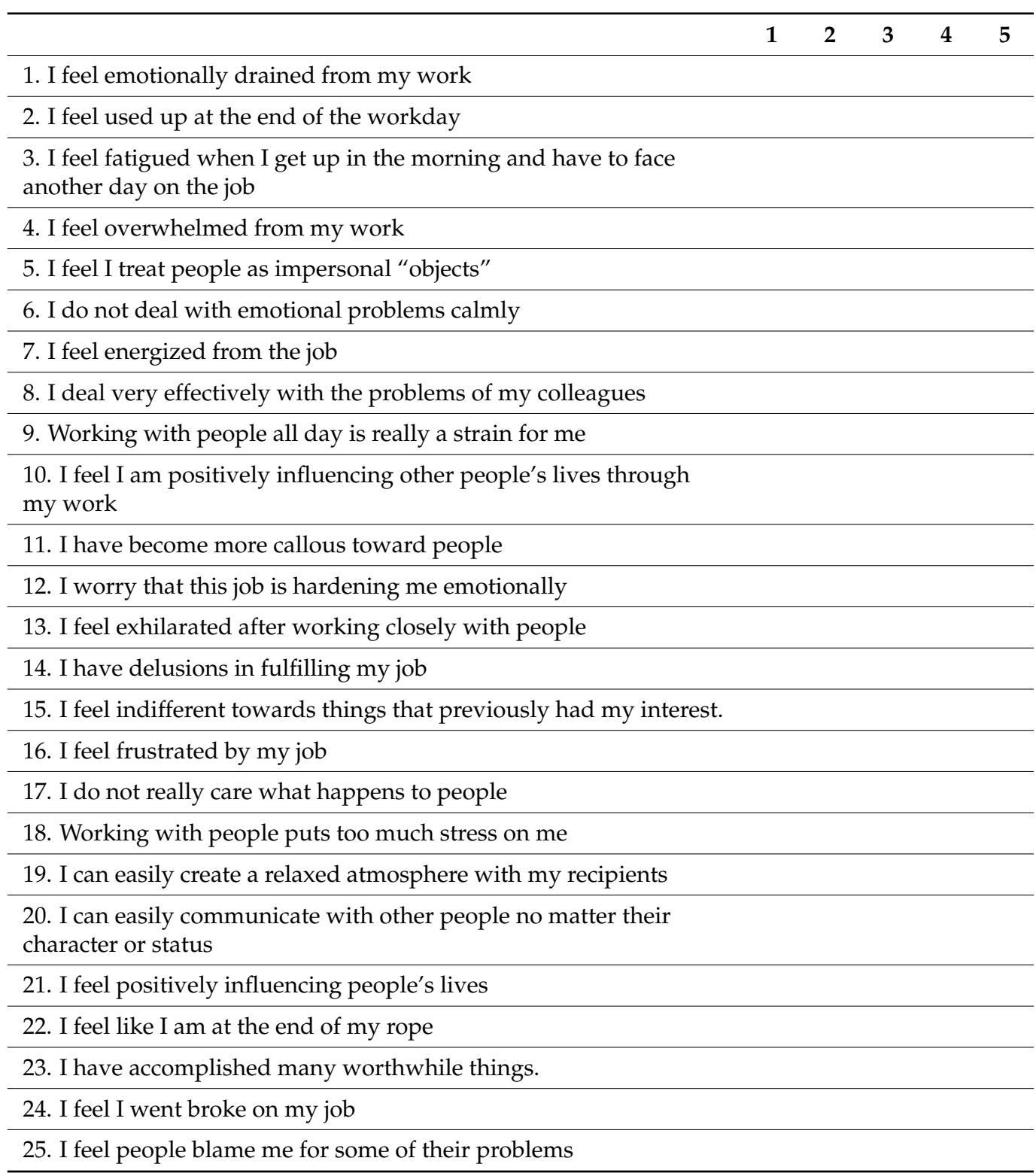

Q 2. Tick the box beside the reply that is closest to how you have been feeling in the past week. Don't take too long over you replies: your immediate is best. 
1. I feel as if I am slowed down:

$\square$ Nearly all the time/ $\square$ Very often $/ \square$ Sometimes $/ \square$ Not at all

2. I get a sort of frightened feeling like 'butterflies' in the stomach:

$\square$ Not at all/ $\square$ Occasionally/ $\square$ Quite Often/ $\square$ Very Often /

3. I have lost interest in my appearance:

$\square$ Definitely

$\square$ I don't take as much care as I should

$\square$ I may not take quite as much care

$\square$ I take just as much care as ever

4. I feel restless as I have to be on the move:

$\square$ Very much indeed/ $\square$ Quite a lot/ $\square$ Not very much/ $\square$ Not at all

5. I look forward with enjoyment to things:

$\square$ As much as I ever did

$\square$ Rather less than I used to

$\square$ Definitely less than I used to

$\square$ Hardly at all

6. I get sudden feelings of panic:

$\square$ Very often indeed/ $\square$ Quite often $/ \square$ Not very often/ $\square$ Not at all

7. I can enjoy a good book or radio or TV program:

$\square$ Often/ $\square$ Sometimes/ $\square$ Not often/ $\square$ Very seldom

Q 3. I meet, at least once a month to be supervised in my work with ...

My supervisor who ...

My mentor who ...

One or more teammates who ...

Nobody (go to Q4)

Table A2. 1-very rarely/2-rarely/3-sometimes/4-frequently/5-very frequently.

\begin{tabular}{l}
\hline \\
\begin{tabular}{l} 
1. Treats me with respect and dignity \\
\hline 2. Turns supervision into a constructive learning process
\end{tabular} \\
\hline 3. Helps me develop skills specific to my job \\
\hline 4. Focuses on the development of my strengths \\
\hline 5. Involves me in the supervision process \\
\hline 6. Makes me feel accepted and respected as a person \\
\hline 7. Approaches both emotions and content of discussions properly \\
\hline 8. Motivates me to assess my own performance/behaviour \\
\hline 9. Instils a sense of competence \\
\hline 10. Supports my interpersonal style \\
\hline 11. Listens to the things that concern me with empathy \\
\hline 12. Is open to feedback from me \\
\hline 13. Helps me reduce defences in supervision \\
\hline 14. Encourages opinions, questions, and concerns related to practice \\
\hline 15. Provides supportive discussion opportunities regarding the \\
challenges I need to face \\
\hline 16. Is flexible enough to encourage spontaneity and creativity \\
\hline 17. Encourages the use of new, diversified techniques \\
\hline 18. Helps me understand and define concrete, specific goals \\
\hline 19. Validates the things I am concerned about \\
\hline
\end{tabular}


Table A2. Cont.

\begin{tabular}{llllll}
\hline & 1 & 2 & 3 & 4 & 5 \\
\hline 20. Provides useful feedback & & & & \\
\hline 21. Allows and encourages self-assessment & & & \\
\hline 22. Explains assessment criteria clearly & & & \\
\hline 23. Applies performance assessment criteria correctly & & & \\
\hline 24. Understands my needs and meets them efficiently & & \\
\hline 25. Is full of support and compassion
\end{tabular}

Q 4. Read the following statements carefully and tick only a box next to each statement, depending on the option that suits you best. The values have the following correspondences:

Table A3. 0-never/1-sometimes /2-most of the time/3-always.

\begin{tabular}{|c|c|c|c|c|}
\hline & $\mathbf{0}$ & 1 & 2 & 3 \\
\hline 1. My religious beliefs make me happy. & & & & \\
\hline $\begin{array}{l}\text { 2. I read and reflect on those in the holy scriptures for at least } \\
\text { half an hour a day. }\end{array}$ & & & & \\
\hline 3. I pray in public. & & & & \\
\hline 4. When trying to solve a problem, I ask God for help. & & & & \\
\hline 5. When I do something wrong, I ask for God's forgiveness. & & & & \\
\hline 6. I talk with others about my religious beliefs & & & & \\
\hline 7. I give money based on my religious beliefs. & & & & \\
\hline $\begin{array}{l}\text { 8. When something bad happens, I know God is trying to } \\
\text { make me }\end{array}$ & & & & \\
\hline stronger. & & & & \\
\hline 9. I volunteer to help others based on my religious beliefs. & & & & \\
\hline $\begin{array}{l}\text { 10. When bad things happen, I know God will show me } \\
\text { the answers. }\end{array}$ & & & & \\
\hline
\end{tabular}

Q 5. Factual data

1. Gender $\square$ Male $\square$ Female

2. Age: $\square$ 21-30 $\square$ 31-40 $\square$ 41-50 $\square$ 51-60 $\square 60+$

3. Last educational institutions graduated from

$\square$ Highschool

$\square$ College

$\square$ Master

$\square$ Doctorate

4. County

5. Work environment $\square$ urban $\square$ rural

6. Seniority $\square 0$ - 5 years $\square$ 6-15 years $\square$ 16-30 years $\square 30$ + years

7. The institution I work in benefits from financial support mainly from

$\square$ The State

$\square$ Sponsors from outside the institution

$\square$ Members

$\square$ Do not know 


\section{References}

1. O'Donoghue, K.; Tsui, M.-S. Social Work Supervision Research (1970-2010): The Way We Were and the Way Ahead. Br. J. Soc. Work. 2015, 45, 616-633. [CrossRef]

2. Carroll, M. One More Time: What Is Supervision? Psychother. Aust. 2007, 13, 34-40.

3. Carpenter, J.; Webb, C.; Bostock, L.; Coomber, C. Effective Supervision in Social Work and Social Care. Research Briefing; Social Care Institute for Excellence: London, UK, 2015.

4. $\quad$ O'Donoghue, K. Restoring Social Work Supervision; Dunmore Press: Palmerston North, New Zealand, 2003.

5. Runcan, P.L. Supervision in Educational, Social and Medical Services Professions; Cambridge Scholars Publishing: Newcastle-uponTyne, UK, 2013.

6. Dan, V.-T. An Exhaustive View on Supervision in Social Work: History, Evolution, Current Trends. Rev. Asistență Soc. 2017, $16,147-159$.

7. Mira, J.J.; Cobos-Vargas, Á.; Astier-Peña, M.P.; Pérez-Pérez, P.; Carrillo, I.; Guilabert, M.; Pérez-Jover, V.; Fernández-Peris, C.; Vicente-Ripoll, M.A.; Silvestre-Busto, C.; et al. Addressing Acute Stress among Professionals Caring for COVID-19 Patients: Lessons Learned during the First Outbreak in Spain (March-April 2020). Int. J. Environ. Res. Public Health 2021, $18,12010$. [CrossRef] [PubMed]

8. The Association for Pastoral Supervision \& Education. Definition and Ethos. Available online: https://www.pastoralsupervision. org.uk/home/about/definition-and-ethos/ (accessed on 23 April 2019).

9. Biserica Ortodoxă Română la 31 Decembrie 2014/1 Ianuarie 2015. Cifre şi Date. Available online: http:/ / patriarhia.ro/images/ pdf_2015/SINTEZA_date_2014.pdf (accessed on 10 April 2019).

10. Lonne, R.L. Social workers and human service practitioners. In Occupational Stress in the Service Professions; Dollard, M.F., Winefield, A.H., Winefield, H.R., Eds.; Taylor \& Francis: London, UK, 2003; pp. 281-310.

11. Conrad, D.; Kellar-Guenther, Y. Compassion fatigue, burnout, and compassion satisfaction among Colorado child protection workers. Child Abus. Negl. 2006, 30, 1071-1080. [CrossRef]

12. Bride, B.E.; Hatcher, S.S.; Humble, M.N. Trauma Training, Trauma Practices, and Secondary Traumatic Stress Among Substance Abuse Counsellors. Traumatology 2009, 15, 96-105. [CrossRef]

13. Louth, J. Understanding Vicarious Trauma. Soc. Work. Talk 2020, 7, 17-18.

14. Maslach, C.; Goldberg, J. Prevention of burnout: New perspectives. Appl. Prev. Psychol. 1998, 7, 63-74. [CrossRef]

15. Maslach, C.; Schaufeli, W.B.; Leiter, M.P. Job Burnout. Annu. Rev. Psychol. 2001, 52, 397-422. [CrossRef]

16. Schaufeli, W.B.; Maslach, C.; Marek, T. (Eds.) Professional Burnout: Recent Developments in Theory and Research; Taylor \& Francis: Washington, DC, USA, 1993.

17. Siu, O.L.; Ng, T.K. Family-to-Work Interface and Workplace Injuries: The Mediating Roles of Burnout, Work Engagement, and Safety Violations. Int. J. Environ. Res. Public Health 2021, 18, 11760. [CrossRef]

18. Cena, L.; Rota, M.; Calza, S.; Janos, J.; Trainini, A.; Stefana, A. Psychological Distress in Healthcare Workers between the First and Second COVID-19 Waves: The Role of Personality Traits, Attachment Style, and Metacognitive Functioning as Protective and Vulnerability Factors. Int. J. Environ. Res. Public Health 2021, 18, 11843. [CrossRef]

19. Dima, G.; Meseșan Schmitz, L.; Simon, M.-C. Job Stress and Burnout among Social Workers in the VUCA World of COVID-19 Pandemic. Sustainability 2021, 13, 7109. [CrossRef]

20. Jihn, C.-H.; Kim, B.; Kim, K.S. Predictors of Burnout in Hospital Health Workers during the COVID-19 Outbreak in South Korea. Int. J. Environ. Res. Public Health 2021, 18, 11720. [CrossRef] [PubMed]

21. Rivas, N.; López, M.; Castro, M.-J.; Luis-Vian, S.; Fernández-Castro, M.; Cao, M.-J.; García, S.; Velasco-Gonzalez, V.; Jiménez, J.-M. Analysis of Burnout Syndrome and Resilience in Nurses throughout the COVID-19 Pandemic: A Cross-Sectional Study Int. J. Environ. Res. Public Health 2021, 18, 10470. [CrossRef] [PubMed]

22. Długosz, P.; Liszka, D. The Relationship between Mental Health, Educational Burnout and Strategies for Coping with Stress among Students: A Cross-Sectional Study of Poland. Int. J. Environ. Res. Public Health 2021, 18, 10827. [CrossRef]

23. Huang, C.; Xie, X.; Cheung, S.P.; Zhou, Y.; Ying, G. Job Demands, Resources, and Burnout in Social Workers in China: Mediation Effect of Mindfulness. Int. J. Environ. Res. Public Health 2021, 18, 10526. [CrossRef]

24. Meek, K.R.; McMinn, M.R.; Brower, C.M.; Burnett, T.D.; McRay, B.W.; Ramey, M.L.; Swanson, D.W.; Villa, D.D. Maintaining Personal Resiliency: Lessons Learned from Evangelical Protestant Clergy. J. Psychol. Theol. 2003, 31, 339-347. [CrossRef]

25. Dos Santos, L.M. The Relationship between Workforce Sustainability, Stress, and Career Decision: A Study of Kindergarten Teachers during the COVID-19 Pandemic. Sustainability 2021, 13, 11521. [CrossRef]

26. Karacic, J.; Bursztajn, H.J.; Arvanitakis, M. Who Cares What the Doctor Feels: The Responsibility of Health Politics for Burnout in the Pandemic. Healthcare 2021, 9, 1550. [CrossRef]

27. Sălășan, C.; Rață, G. Social Farming in Romania: A Synchronic Approach. Lucr. Ştiinţifice 2019, 21, 89-96.

28. Carey, L.; Rumbold, B.; Newell, C.; Aroni, R. Bioethical issues and healthcare chaplaincy in Australia. Health Soc. Care Chaplain. 2013, 9, 23-30. [CrossRef]

29. Stevenson, O. Editorial. Child Fam. Soc. Work. 2005, 10, 185-186. [CrossRef]

30. Wallbank, S.; Hatton, S. Evaluation of clinical supervision delivered to health visitors and school nurses. Community Pract. 2011, $84,21-25$. 
31. Hyrkas, K.; Appelqvist-Schmidlechner, K.; Haataja, R. Efficacy of clinical supervision: Influence on job satisfaction, burnout and quality of care. J. Adv. Nurs. 2006, 55, 521-535. [CrossRef]

32. Wallbank, S. Effectiveness of individual clinical supervision for midwives and doctors in stress reduction: Findings from a pilot study. Evid.-Based Midwifery 2010, 8, 65-71.

33. Bogo, M.; Paterson, J.; Tufford, L.; King, R. Interprofessional clinical supervision in mental health and addiction: Toward identifying common elements. Clin. Superv. 2011, 30, 124-140. [CrossRef]

34. Kavanagh, D.J.; Spence, S.H.; Strong, J.; Wilson, J.; Sturk, H.; Crow, N. Supervision practices in allied mental health: Relationships of supervision characteristics to perceived impact and job satisfaction. Ment. Health Serv. Res. 2003, 5, 187-195. [CrossRef]

35. Landau, R.; Baerwald, P. Professional socialization, ethical judgment and decision making orientation in social work. J. Soc. Serv. Res. 1999, 25, 57-75. [CrossRef]

36. Maslach, C.; Jackson, S.E.; Leiter, M.P. Maslach Burnout Inventory Manual, 3rd ed.; Consulting Psychologists Press: Palo Alto, CA, USA, 1996

37. Dan, V.-T. Rolul Supervizării în Prevenirea Epuizării Profesionale a Asistenților Sociali și Clericilor din România Implicați în Procesul Recuperării Persoanelor Aflate în Dificultate. [Role of Supervision in Preventing Burnout of Social Assistants and Clerics in Romania Involved in the Recovery of People in Difficulty]. Ph.D. Thesis, West University of Timișoara, Timișoara, Romania, 2019.

38. Stern, A.F. The Hospital Anxiety and Depression Scale. Occup. Med. 2014, 64, 393-394. [CrossRef]

39. Zigmond, A.S.; Snaith, R.P. The Hospital Anxiety and Depression Scale. Acta Psychiatr. Scand. 1983, 67, 361-370. [CrossRef]

40. Barnard, L.K.; Curry, J.F. The Relationship of Clergy Burnout to Self-Compassion and Other Personality Dimensions. Pastor. Psychol. 2011, 61, 149-163. [CrossRef]

41. Runcan, R. Facebook Mania or How Virtual Communication Impacts Human Relationships; Editura de Vest: Timişoara, Romania, 2020.

42. Mullarkey, K.; Keeley, P.; Playle, J. Multiprofessional clinical supervision: Challenges for mental health nurses. J. Psychiatr. Ment. Health Nurs. 2002, 8, 205-211. [CrossRef] [PubMed]

43. Grauel, T. Overseeing the overseers: Supervision of Christian Clergy in Australia. In Super-Vision in the Helping Professions a Practical Approach; McMahon, M., Patton, W., Eds.; Prentice Hall: French Forest, Australia, 2002; pp. 261-272.

44. Kadushin, A.; Harkness, D. Supervision in Social Work, 4th ed.; Columbia University Press: New York, NY, USA, 2002. 